A larger prospective study with formal follow-up of non-attenders in a psychiatric follow-up clinic would produce invaluable data.

\section{References}

BaEKLAND, F. \& Lundwall, L. (1975) Dropping out of treatment. A critical review. Psychological Bulletin, 82, 738-783.
Department of Health and Social Security (1984) The facilities and services of mental illness and mental handicap. Hospitals in England (1977-79). Statistical and Research Report No. 26. London: HMSO.

Frankel, S., Farrow, A. \& West, R. (1989) Nonattendance or non-invitation? A case control study of failed out-patient appointments. British Medical Journal. 298, 1343-1345.

JoHnson, D. A. W. (1973) An analysis of out-patient services. British Journal of Psychiatry, 22, 301-306.

\title{
The absconder and the Hospital Order
}

\author{
ADERSH KAUL, Registrar in Forensic Psychiatry, Towers Hospital, Leicester LE5 0TD; \\ and MAGGIE WHITTAKER, Senior Social Worker, Broadmoor Hospital, Crowthorne, \\ Berkshire RG11 7EG
}

The Mental Health Services have been accused of providing a 'soft option' to offenders and this charge is highlighted in cases where the mentally disordered offender absconds (hereafter called the absconder) from the hospital. Society just about manages to accept the disposal of disturbed offenders to hospital, which it sees as providing at least some limited incarceration, but in the event of an offender absconding the whole dilemma of offenders considered to be in need of treatment is thrown into question. The Responsible Medical Officer (RMO) is concerned with issues of treatment, public safety and his/her responsibility to the Courts and society; and thus finds himself/herself in the conflicting roles of a doctor and an agent of social control. This paper attempts to address some of the issues surrounding the areas of the rights of the patient, the dilemma faced by the clinicians and the rightful use of the powers of the doctor and of the State in relation to Hospital Order and the absconder.

\section{Treatment or punishment}

The Hospital Order is generally considered as a humane alternative to the sentencing of mentally abnormal offenders to prison. It is imposed explicitly for the purpose of treatment rather than punishment and by imposing the Hospital Order the court channels the mentally abnormal offender into the mental health rather than the penal system. The primacy of therapeutic rather than a punitive consideration has been emphasised in a Government White Paper, Department of Health and Social Security (1978) which states "in making the Order the court is placing the patient in the hands of the doctors, foregoing any question of punishment and relinquishing from then onwards its own control over him". Bluglass (1983) reminds us "it is an alternative disposal and the person becomes a patient not a prisoner".

Despite the therapeutic spirit behind the Hospital Order, it is not difficult to see how the deprivation of liberty coupled with treatment without consent may be interpreted as a form of punishment. Potas (1982) points out that the assumption that a Hospital Order is "not punitive is to misconceive the objective of the sanction. It shares with imprisonment the consequence of depriving an individual of his or her liberty. Like imprisonment it offers protection to the community by separating inmates from normal 
societal intercourse." One of the areas in which this therapeutic v. punitive conflict expresses itself is the case of the patient on Hospital Order who absconds. Do the absconders abscond because they are too ill to know what is good for them or because they think they are well enough to survive in the community and are being unnecessarily detained?

\section{Historical perspective}

To understand the rights of the absconder it is important to examine the historical perspective. The Lunacy Act of 1890 provided that an absconding patient could not be retaken after successfully remaining at large for 14 days, this being assumed to indicate that he/she was competent enough not to justify compulsory detention. This was also seen as a precautionary measure against the 19th century belief that it was too easy for relatives who wished to secure control of someone's property by having him/ her committed to an asylum with little hope of release (Butler, 1975).

With the advent of the 1959 Mental Health Act a limit was placed on the period within which absconders could be apprehended and returned to the hospital (Section 40). The 1959 Act divided mental disorder into the categories of mental illness, subnormality, severe sub-normality and psychopathic disorder. The mentally ill and the severely subnormal offenders possibly regarded as 'severe' forms, legally regained their freedom if they absented from the hospital for more than 28 days whereas the psychopathic or sub-normal patient had to remain absent for more than six months to avoid compulsory return to hospital. Provisions of Section 40 did not apply to patients on a restriction order who could be retrieved irrespective of the period of absconsion.

The 1960s saw the increasing influence of civil libertarians in formulation of public policy. The decarceration/deinstitutionalisation movement was gathering momentum and so was the criticism of the powers of the State and that of the psychiatrist. The 1959 Act which had been hailed as an enlightened and liberal statute was now being seen as somewhat neglectful of patients' rights. Before attempting to examine the contemporary legal position vis-à-vis the Hospital Order and the absconder, we would like to mention briefly the issues that in our opinion need to be taken into account.

\section{Relevant issues}

(a) 'Treatment': The function of a Hospital Order is primarily that of treatment of the mental disorder - and the offenders have a right to treatment whether or not they acknowledge it. (b) 'Treatment compliance': The absconder could be seen as a person who does not wish to receive treatment. Is it appropriate or even possible to treat somebody who is unwilling to be helped?

(c) 'Legal process': This would include factors such as (i) retribution, i.e. paying the debt to society, (ii) tariff, i.e. the minimum period for which society might consider the above debt should be paid, (iii) deterrence and (iv) respect for the institutions that society has created, e.g. the law and Courts.

(d) 'Preventive detention': The offences committed have in some cases included harm to others. Since the offence is seen as a function of the mental disorder the risk to public safety has to be taken into consideration while making the Order.

The above points were taken into account by the Butler Committee (1975) which gave careful consideration to the question of mentally abnormal offenders. Representations had been made to the Butler Committee (1975) that "it was indefensible that an offender who has been sent to hospital (in preference, perhaps, to being committed to prison) should be able just to walk out and evade completely the Court's order merely by remaining at large, in some cases for as short a time as $\mathbf{2 8}$ days". This could be viewed as the need for the Hospital Order to take into consideration the 'legal process' issue, as it sees the absconder making a mockery of the authority of the court. The Committee's deliberations on the issues of 'preventive detention' and 'treatment compliance' led them to state "it is the doctor who is best able to judge the prospective risk if the patient remains at large and to what extent the patient might be willing or able to respond to medical treatment should he be returned". They recommended that the RMO should decide whether or not to seek the return of the patient during the duration of the Order. This would have also satisfied the critics who felt that the absconder should not be allowed to obstruct the authority of the Court by remaining at large for a sufficient time. The final recommendations of the Committee seem to have achieved a relatively fine balance between the four issues of 'treatment', 'legal process', 'treatment compliance' and 'preventive detention'.

\section{Current position}

However, it seems that the Mental Health Act (1983) has not taken up the proposals of the Butler Committee regarding the absconding patient. In terms of the Hospital Order the status of the absconding patient is the same as part 2 of the Act, Section 18(4) of which states "a patient shall not be taken into custody under this section after the expiration of the 
period of 28 days beginning with the first day of his absence without leave; and the patient who has not returned or been taken into custody under this Section within this set period shall cease to be liable to be detained ... after expiration of that period". This of course does not apply to Restriction Orders (Section 41) where the absconder is liable to be retrieved irrespective of the period of absconsion. The 1983 Act sees the Hospital Order in a therapeutic role similar to Section 3 with the only major difference being absence of the right to have a tribunal within the first six months. The Act deals with the issues of public safety and preventive detention with the assumption that the patients under Hospital Order are not a great risk to the public, i.e. similar to Section 3, because had they been so, the court would have added restrictions to the Hospital Order.

Unfortunately the issue of 'public safety' and preventive detention is not as clear cut as the 1983 Act appears to state. The Act seems to assume that those mentally abnormal offenders who are not considered a risk are given a simple Hospital Order (Section 37) whereas those who are deemed to be such a risk are placed on a Restriction Order (Section 41). Unfortunately, this simple dichotomy is not consistent with what is seen in practice. If the above were the case, then we would have seen more Section 37 Orders being made to open psychiatric hospitals rather than to secure facilities, as in theory if these people are not a risk to public safety they should not need a secure environment. In practice, the clinicians find that the assessment of risk is in most cases a 'grey' area. They hope that they can achieve a shift towards lessening the risk by treatment but feel frustrated in not being able to treat the patient if he/she absconds and also feel responsible for public safety.

Another cause for concern is that the 1983 Act does not make distinction between the 'severe' (mental illness and severe mental impairment) forms of mental disorder and the 'milder' forms (psychopathic disorder and mental impairment). The assumption in the Lunacy Act of 1890 was that if a mentally abnormal person can survive in the community for a specific period of time, he/she was competent enough not to need compulsory detention. Can we say the same about psychopathic offenders? Can we confidently say that a psychopathic offender who manages to remain at large for more than $\mathbf{2 8}$ days is not a risk to public safety and does not require treatment?

A further problem is that of those offenders who need treatment but whose clinical state and antecedents do not indicate the need for secure environment. They are not deemed to be a risk to public safety and at their worst engage only in minor offending, e.g. burglary. Due to repeated absconsions they continually frustrate the attempts by the psychiatric services to satisfy the patient's rights to treatment and the clinical team's responsibility to the Courts. Persistent absconders of this type may eventually be placed in a secure environment purely to facilitate their treatment rather than because they are a risk to the public. This poses a conflict to the psychiatrists whose primary role is not that of a custodian. (This has not been helped by the current reduction in facilities and resources in the community and NHS.)

It seems that in its preoccupation with preserving patients' rights, the 1983 Act has somewhat neglected the issue of public safety. It is argued here that the Hospital Order should continue to be seen broadly as a treatment and not a punitive option but the public safety does not have to be neglected to avoid appearing punitive. When mental disorder has either led or contributed towards the offence, the offending behaviour could be conceptualised as symptomatic of the disorder. This leads to the logical conclusion that chances of reoffending are higher if the patient remains ill. A careful consideration of the risk to public safety while making decisions about discharge from the hospital thus becomes an assessment of one of the clinical dimensions of the mental disorder and not that of tariff/retribution.

\section{Comment}

Doctors are generally willing to accept responsibility for performing the dual role of clinician and agent of the State but current legislation sometimes makes the discharge of this responsibility difficult. In terms of the absconder it might be best to follow the original recommendation of the Butler Committee. The RMO and the clinical team are relatively in the best position to assess the mental disorder and the treatment that could or could not be provided. They should be able to decide whether or not to seek the return of the absconder during the duration of the order. Currently the onus seems to be on the absconder to avoid detection, but it would appear to be in keeping with the therapeutic spirit of the Hospital Order if the decision to retrieve was made on clinical consideration and not on an ability to avoid detection.

\section{References}

Bluglass, R. (1983) A Guide to the Mental Health Act 1983. London: Churchill Livingstone.

BUTLER, LORD R. A. (Chairman) (1975) Report of the Committee on Mentally Abnormal Offenders, Cmnd 6244. London: HMSO.

Department of Health and Social Securtry (1978) Review of the Mental Health Act 1959. Cmnd 7320. London: HMSO.

Mental Health Act (1983) London: HMSO.

Potas, I. (1982) Just Desserts for the Mad. Canberra: Australian Institute of Criminology. 